\title{
Evaluation of a Macro Lump Plasticity Model for Reinforced Concrete Beam-Column Joint under Cyclic Loading
}

\author{
Purnomo, J. ${ }^{*}$, Octaviani, V. ${ }^{2}$, Chiaulina, P. K. ${ }^{3}$, and Chandra, J. ${ }^{1}$
}

\begin{abstract}
Lateral deformations of reinforced concrete (RC) frames under extreme seismic excitation are highly affected by the stiffness of their beam-column joints. Numerous models have been proposed to simulate the responses of $\mathrm{RC}$ beam-column joint under cyclic loading. Development of RC beam-column joint model based on macro modeling using spring elements becomes more popular because of its considerably simple application for seismic performance evaluation purposes. In this study, a simple modification to previously developed macro-spring element-based model for RC beam-column joint is done and is used to simulate the behavior of seven external and five internal RC joints under cyclic loading in SAP2000. The model consists of several spring elements to define column, beam, joint, and bond-slip responses according to its individual moment-rotation relationships. Overall, the analysis results show that the modified model can simulate well the cyclic behavior of RC beam-column joints when are compared to previously available experimental results.
\end{abstract}

Keywords: RC beam-column joint; cyclic behavior; macro spring model.

\section{Introduction}

Recently, building codes require higher demand on structural performance against seismic loading to account for effects when an extreme earthquake occurs. It is obvious that the ductility of a structure can be judged by its ability to provide large inelastic drift when such severe seismic excitation is applied [1]. Previously, in determining the structural drift, most researchers and practitioners measure the story drift based on frame stiffness, i.e. stiffness provided by gravity and lateral elements' stiffness. Meanwhile, the stiffness contribution from the connection between frame elements or so-called joint is neglected by assuming it as rigid area of concrete. This is, later, found not true since the stiffness of beam-column joint contributes significant deformation [1] to the entire structure at extreme lateral loading.

Beam-column joints contribute substantial portion as much as $75 \%$ to overall structural drift [1]. Due to this fact, numerous experimental tests as well as numerical simulation and modeling have been conducted to study its behavior under cyclic loading.

${ }^{1}$ Civil Engineering Department, Faculty of Civil Engineering and Planning, Petra Christian University, Jl. Siwalankerto 121-131, Surabaya 60236, INDONESIA

${ }_{2}^{2}$ Praktira Consultant

3 Alumnus of Civil Engineering Department, Faculty of Civil Engineering and Planning, Petra Christian University, Jl. Siwalankerto 121-131, Surabaya 60236, INDONESIA

*Corresponding author; Email: jpurnomo@petra.ac.id

Note: Discussion is expected before November, $1^{\text {st }} 2020$, and will be published in the "Civil Engineering Dimension", volume 23, number 1, March 2021.

Received 22 June 2020; revised 28 June 2020; accepted 10 September 2020.
In case of computational modeling, it is common to model the beam-column joint using rotational hinges and multi-springs. The rotational hinges are usually represented by bilinear or trilinear pushover curve, which is derived from experimental results. As for multi-spring models, separation of three contributing factors in determining beam-column joint stiffness, i.e. bond-slip, beam, and column rupture, is commonly done [2].

The first attempt to the development of reinforced concrete (RC) beam-column joint model was made by Giberson [3] where two inelastic rotational springs placed at the end of elastic elements to study the inelastic behavior of joint and the bending response of frames. In 1974, Otani [4] utilized bilinear envelope curve and assumed sufficient development length to fulfill bond stress demand. Banon et al. [5] proposed an analytical model to predict the behavior of RC frames under seismic excitation by considering bondslip stress as well as sliding shear, and thus was able to accommodate the pinching effect in the hysteresis curve model. A zero-length rotational spring was modeled between the joint and the elastic element, i.e. beam and column, to separate each of its individual response and such it can capture the shear deformation of the beam-column joint [6]. Biddah and Ghobarah [7] came up with a model consisting of a series of rotational springs, which was able to capture shear deformation and bond-slip behavior of beamcolumn joint. Simultaneously, a force-deformation relationship of $\mathrm{RC}$ beam-column joint with transverse reinforcement was proposed.

Another beam-column joint model was proposed by Elmorsi et al. [8] that comprises of a continuum element to represent rigid joint core, line element to 
represent beam and column, and rotational spring to maintain compatibility between the previous two elements. A more extensive beam-column joint model was proposed by Youssef and Ghobarah [9] where joint core was represented by a rectangular rigid member with diagonally connected spring elements. Each face of the rigid member consists of additional three springs that are connected to elastic beam or column elements. Pampanin [10] suggested a momentrotation relationship for beam-column joint. Meanwhile, Lowes and Altoontash [11] proposed a beamcolumn joint model with four nodes representing twelve degree of freedoms. The model was reliable to represent inelastic mechanism of beam-column joint determined by failure of joint core against shear loading and anchorage failure of longitudinal steel reinforcement of beams and columns. Shin and LaFave [12] further used the method proposed by Lowes and Altoontash [11] to investigate the portion of shear deformation in the joint.

Additional beam-column joint model was proposed by Tajiri et al. [13], where numerous spring elements were introduced to represent constitutive concrete material for the column, beam, and joint core, beam shear, and beam bond-slip. Mitra and Lowes [14] proposed a beam-column joint model constructed from shear panel and spring elements. The spring elements connect the internal node, i.e. the face of shear panel, and the external node, which is the end of beam or column element. A numerically nonlinear modeling of beam-column joint was proposed by Magliulo and Ramasco [15] by using lumped plasticity model for beams and multi-spring elements for columns, which made it able to capture the biaxial bending moment interaction in the column. Anderson et al. [16] further extended Biddah and Ghobarah [7] model by proposing a cyclic shear force-deformation relationship for RC beam-column joint with no shear reinforcement.

In 2012, Wang et al. [17] proposed a model to estimate shear strength of beam-column joint by considering the contribution of shear reinforcement in the joint and was validated to an extensive number of experimental test results. Birely [18] also developed a model that comprises of dual-hinge lumped plasticity beam element to model beams framing into columns. Furthermore, in 2013, Yu and Tan [19] proposed a component-based joint model to simulate the structural responses under progressive collapse such as middle column removal scenario. Omidi and Behnamfar [2] advanced beam-column joint model with dual spring at the end of beams and columns, which was the extended version to the model proposed by Birely [18] as well as defining the rigid offset parameter to the beams and columns to capture the behavior of interior beam-column joint. Each spring in the model has its own moment-rotation response representing the nonlinear behavior of beams, columns, and joint. Moreover, a versatile beamcolumn joint model was proposed by Eom et al. [20] in which the beam bond-slip parameters were used to estimate the dissipated energy capacity of the joint. The model was claimed to be simple and can be conveniently applied to performance-based analysis in available computer software.

Based on the previous development of beam-column joint models, researchers have been trying to establish the most reliable numerical approach to correctly incorporate factors affecting the behavior of $\mathrm{RC}$ beam-column joint. The failure mechanisms in beam-column joint are categorized as joint shear failure, beam yielding failure, and bond-slip failure. Each model shares its own strength and weakness, i.e. a more accurate and realistic responses can be achieved with the expense of sophisticated modeling as well as computational running time. In the end of the day, the model should be sufficiently simple yet accurate to be incorporated into structural frames modeling. Among the previously developed model, the model proposed by Omidi and Behnamfar [2] and Eom et al. [20] can be further explored and applied to structural frames analysis.

This study aims to investigate the reliability of a RC beam-column joint lumped plasticity model based on Omidi and Behnamfar [2] and Eom et al. [20] for several interior and exterior joints. The evaluation is done by comparing the hysteretic curves obtained from the model to the experimental results of available literature. Some modifications to the model are then made to accommodate the failure mechanism according to experimental results.

\section{RC Beam-Column Joint Model}

\section{Adopted RC Beam-Column Joint Model}

In this study, the RC beam-column joint was modeled based on Omidi and Behnamfar [2] and Eom et al. [20] with some modifications on the bond-slip model. The adopted model is depicted in Figure 1 where rigid element is defined for joint core region. Two rotational spring elements were defined at each face of rigid joint region, i.e. two column springs and two joint springs with individual moment-rotation responses. Column spring represents the flexural response of column against applied lateral load. In the other hand, joint spring can represent either as well as combination of joint shear strength, beam flexural strength, and bond-slip strength. The later spring element response can be further adjusted to match the behavior of the beam-column joint based on the experimental results from available literature. 


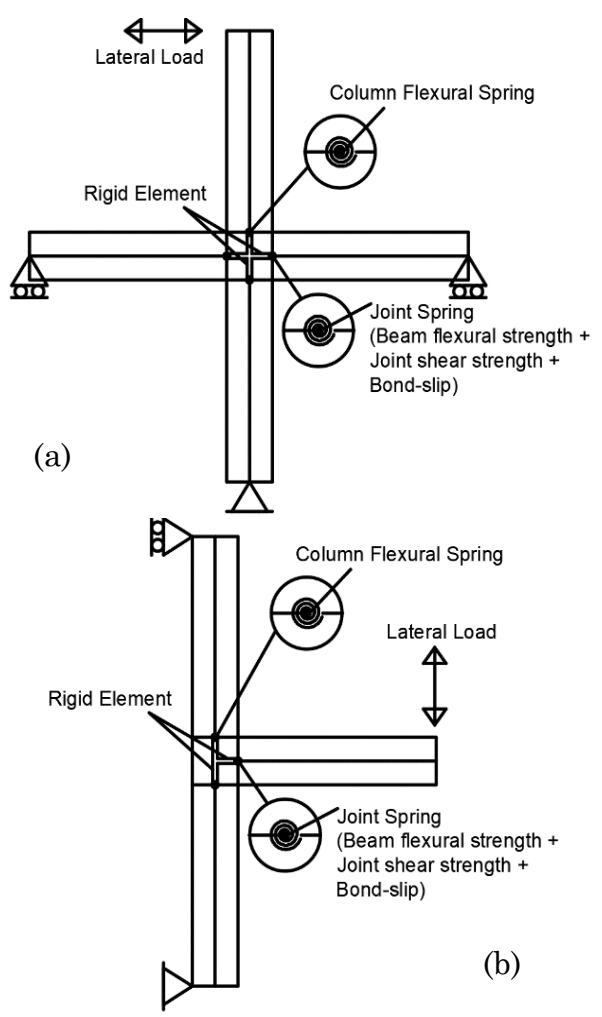

Figure 1. Proposed Beam-column Joint Model for (a) Internal Joint and (b) External Joint

\section{Adopted Bond-Slip Model}

Various research based on continuum modeling were done to investigate the bond stress-slip relationship at contact area between concrete and steel rebars. The first attempt was done by Ngo and Scordelis [21] by proposing a linear elastic element model for simply supported beam. In this model, the bond was model by two orthogonal spring elements connecting continuum points at contact surface between concrete and steel rebars. Same approach was adopted by Nilson [22] with additional definition of nonlinear constitutive material for concrete, steel rebars, and bond-slip. In 1987, Keuser and Mehlhorn [23] proposed a continuous bond-slip interaction between concrete and steel rebars. Filippou [24] used weighted residual method to solve differential equations arose from equilibrium and compatibility of anchored steel rebars. Other finite element model development was done by Monti [25] through flexibility-based element formulation. Also, Ciampi [26] developed numerical scheme to integrate the bond differential equation along the contact area between concrete and steel rebars. Elmorsi [8] proposed a displacement-based bond-slip interpolation function to represent continuum interaction along contact surface between concrete and steel rebars. The material model and monotonic envelope curve for bond-slip [8], which was simplified from Eligehausen et al. [27], is used in this research to model the bond-slip response in the RC beam-column joint and is depicted in Figure 2. The corresponding equations representing the bond-slip behavior are presented in Equations 1, 2, and 3. The bond stress and slip in the equation is denoted by $\tau$ and $\mathbf{s}$, while the parameter defining the factor of confined and unconfined concrete condition, and hooks in confined concrete is represented by $\boldsymbol{\alpha}$. Details values of $\boldsymbol{\alpha}$ can be found in Elmorsi et al. [8].

$$
\begin{aligned}
& \tau=\tau_{1}\left(\frac{s}{s_{1}}\right)^{\alpha}, s \leq s_{1} \\
& \tau=\tau_{1}, s_{1} \leq s \leq s_{2} \\
& \tau=\tau_{1}-\frac{\tau_{1}-\tau_{2}}{s_{3}-s_{2}}\left(s-s_{2}\right) \leq \tau_{3}, s>s_{2}
\end{aligned}
$$

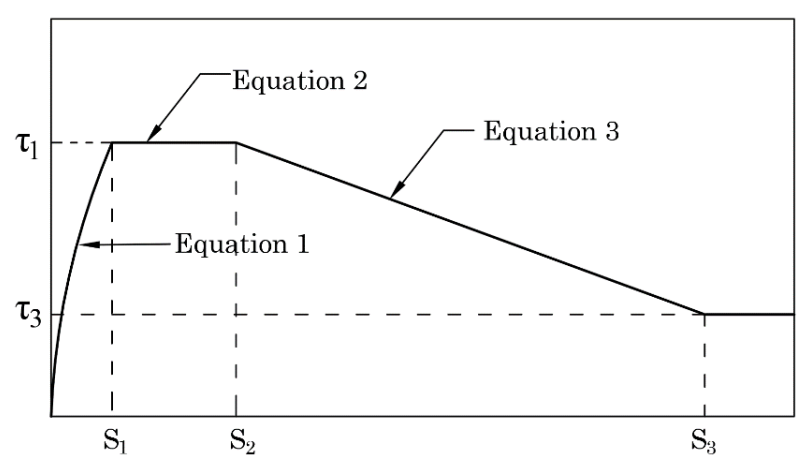

Figure 2. Monotonic Envelope Curve for bond-slip Relationship [8]

\section{Methods}

\section{Defining Nonlinear Behavior}

To incorporate the nonlinear behavior of $\mathrm{RC}$ beamcolumn joint in the model, several parameters in SAP2000 needs to be defined. Firstly, the stressstrain relationship representing the material behavior at elastic and plastic region must be chosen. In this study, a concrete material model based on Mander [28] and steel rebar material model based on Park [29] were selected. One advantage of using Mander concrete model is its capability of representing confined and unconfined concrete response under cyclic loading. The hysteresis type for concrete material, Takeda and Concrete hysteresis model can be used as depicted in Figure 3. Steel rebar material was also defined to incorporate elastic and plastic region as well as the hysteresis type, i.e. kinematic, as shown in Figure 4.

Secondly, plastic hinges for column, beam, and joint was also to be defined. Column and plastic hinges were represented by fiber hinges with hinge length was set to equal 0.1 times the analytical length of the frame element. In this study, fiber P-M2-M3 hinges were selected for columns and beams. The other type of hinges, pivot hinges, were applied to represent the nonlinear behavior of joint core. An example of defining each hinges type, i.e. fiber P-M2-M3 and pivot hinges, was depicted in Figures 5 and 6, respectively. 
The third, a feature in SAP2000 named Section Designer can be used to define the confined and unconfined area of concrete. The concrete area inside shear ties was defined using confined concrete material properties. The concrete area representing the concrete cover was assigned to unconfined concrete material properties. Also, main steel rebars and ties were set to the corresponding material parameters based on reference database. An example of defining section properties using Section Designer is shown in Figure 7.

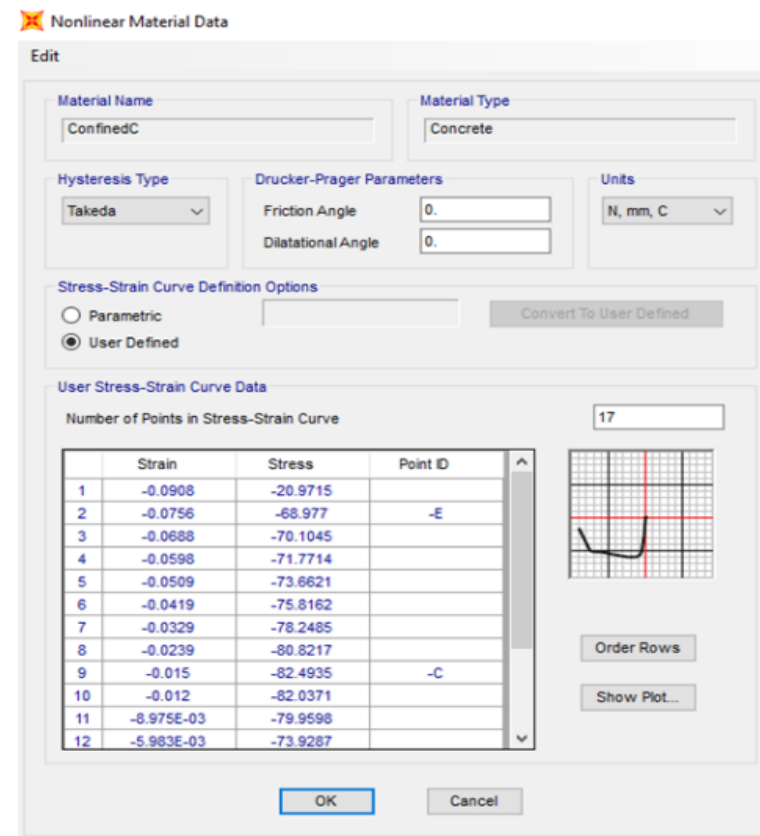

(a)

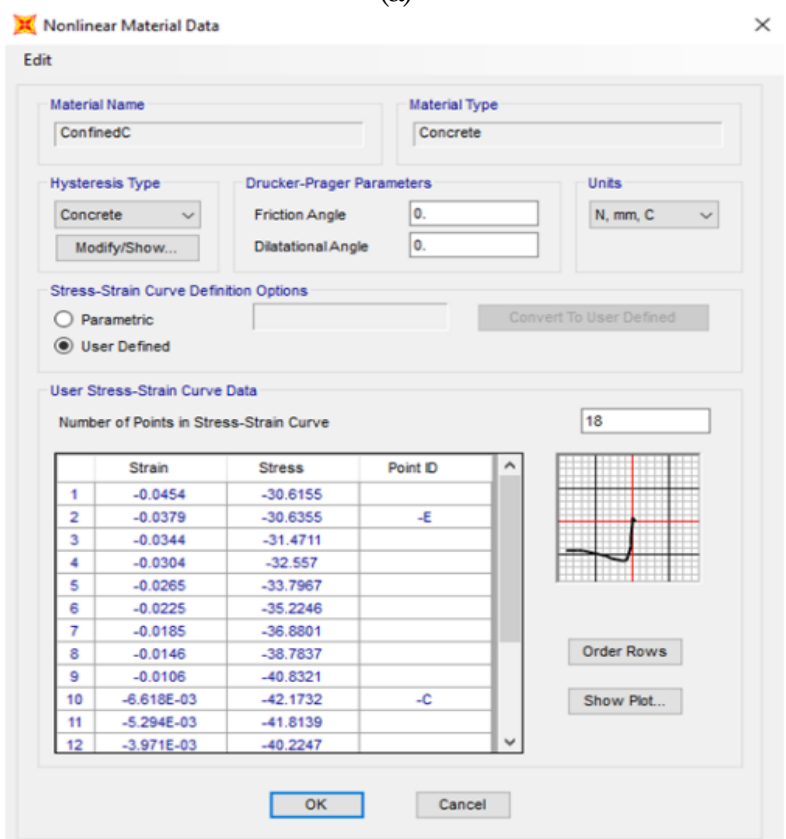

(b)

Figure 3. Concrete Material Model Definition in SAP2000 (a) using Takeda Hysteresis type, (b) using Concrete Hysteresis Type

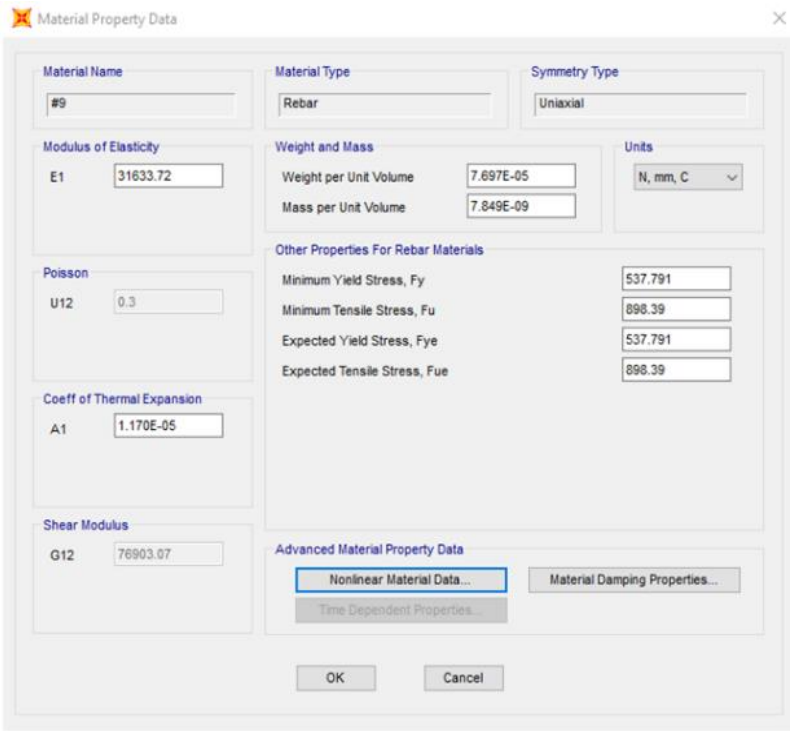

(a)

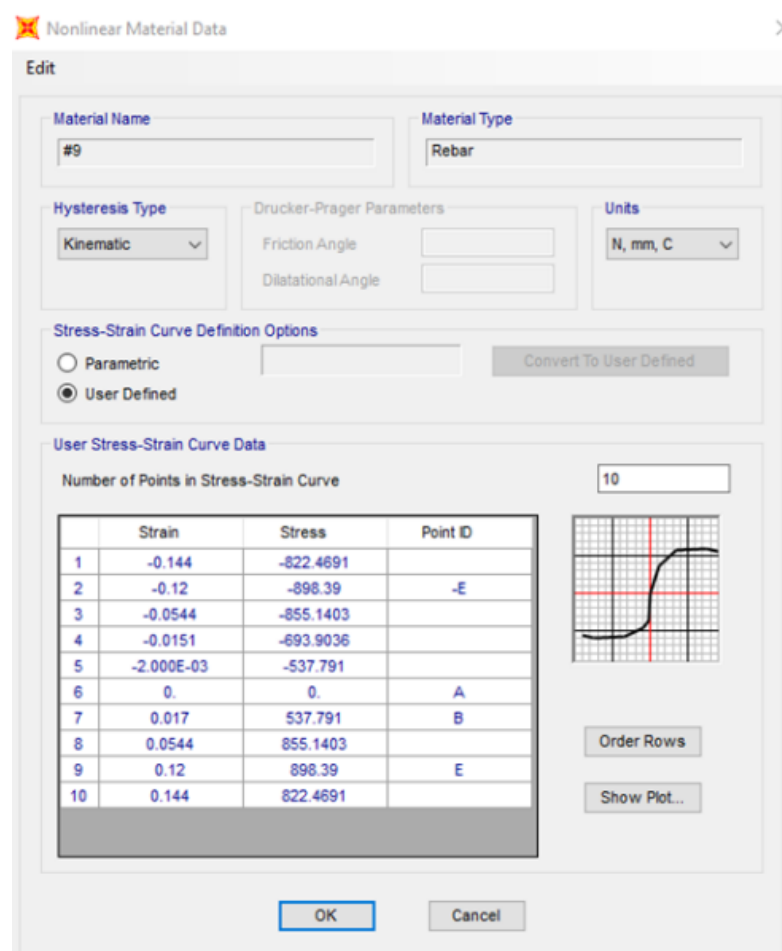

(b)

Figure 4. Steel Rebar Material Definition in SAP2000 (a) Linear Material Properties, (b) Nonlinear Material Properties using Kinematic Hysteresis Type

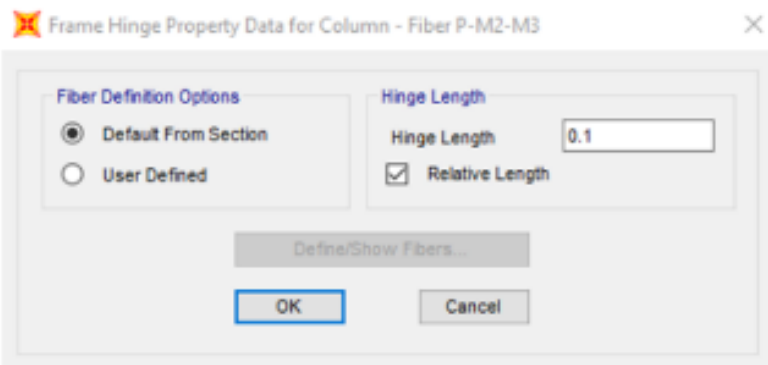

(a) 


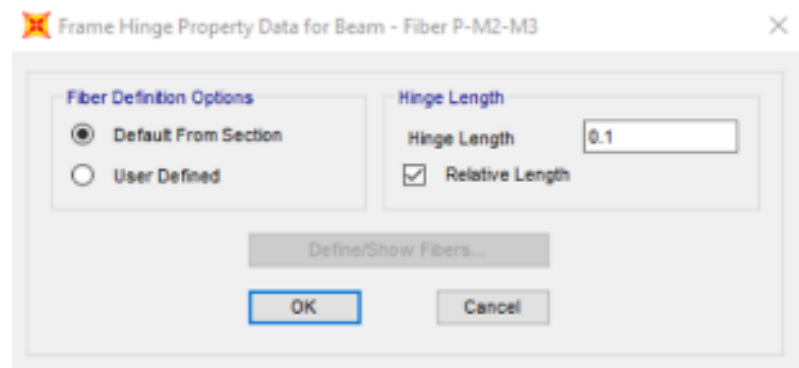

(b)

Figure 5. Fiber P-M2-M3 Hinges Definition (a) for Column, (b) for Beam

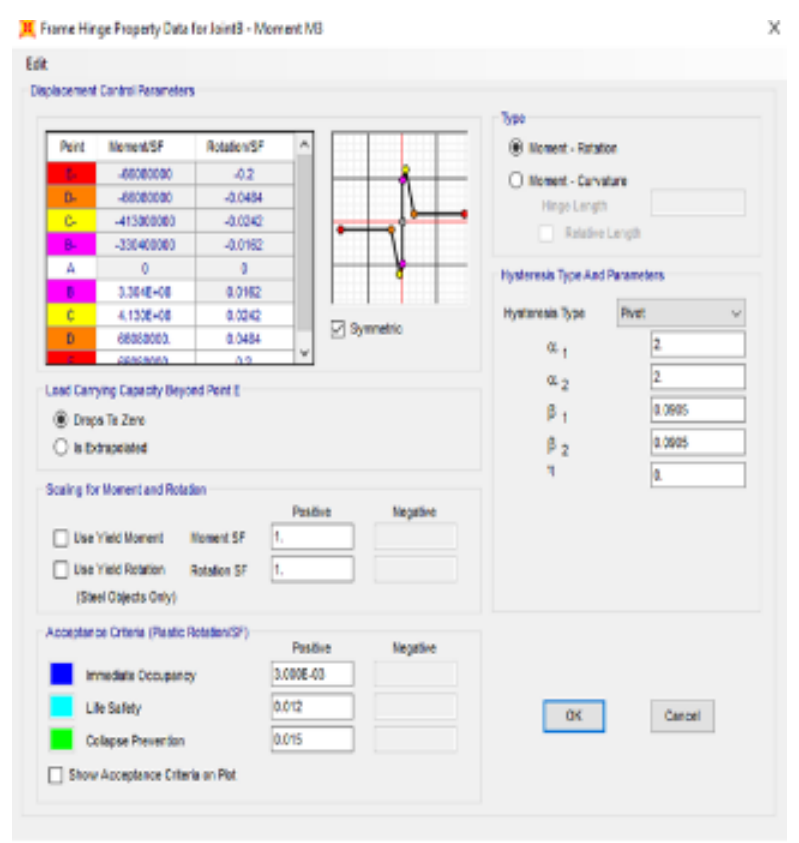

(a)

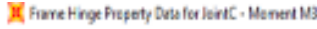

tok

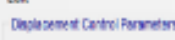

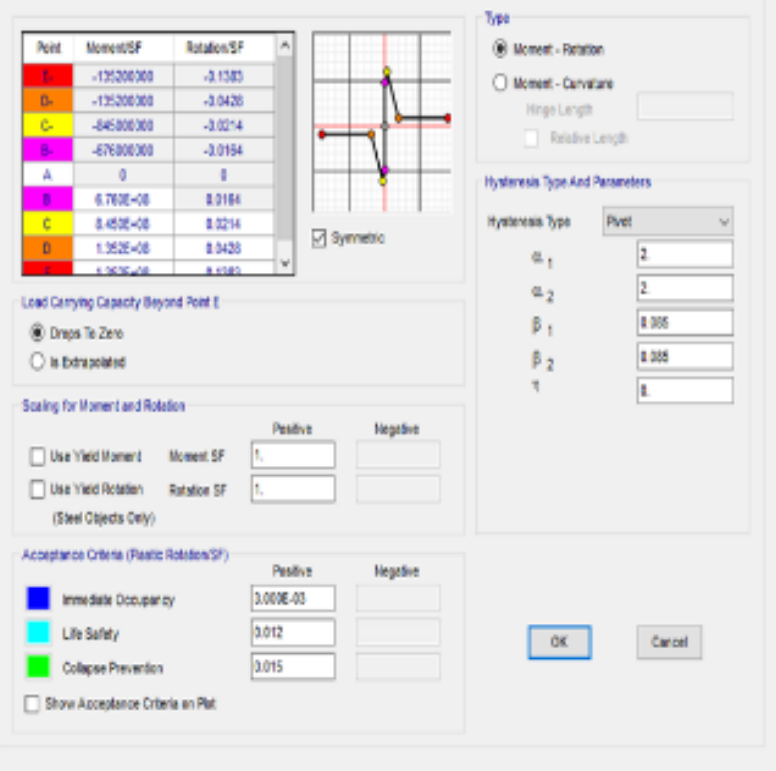

(b)

Figure 6. M3 Hinges Definition for Joints (a) Attached to Beams, (b) Attached to Columns

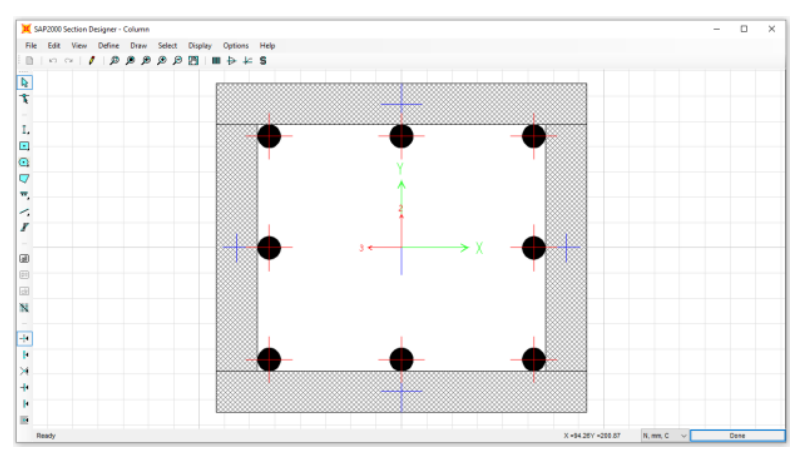

Figure 7. Confined and Unconfined Area of Concrete Section Definition using Section Designer in SAP2000

\section{Defining the Loading History}

The loading history sets were replicated from existing literature, which majority were displacementcontrolled loading cycles. A multi-stages pushover analysis case was chosen to mimic the loading history. Figure 8 shows the load cases definition. Further parameters for nonlinear analysis were set to default values.

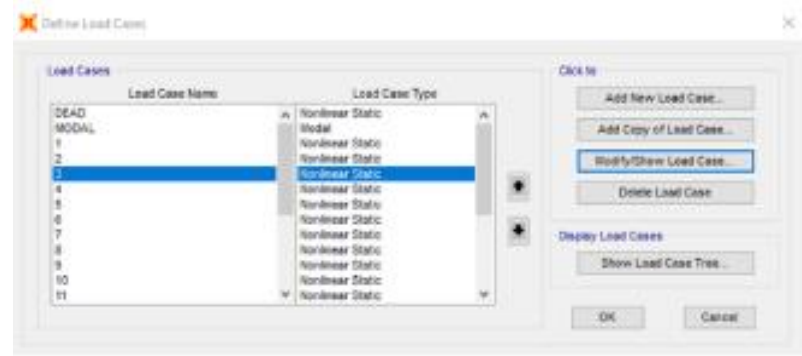

(a)

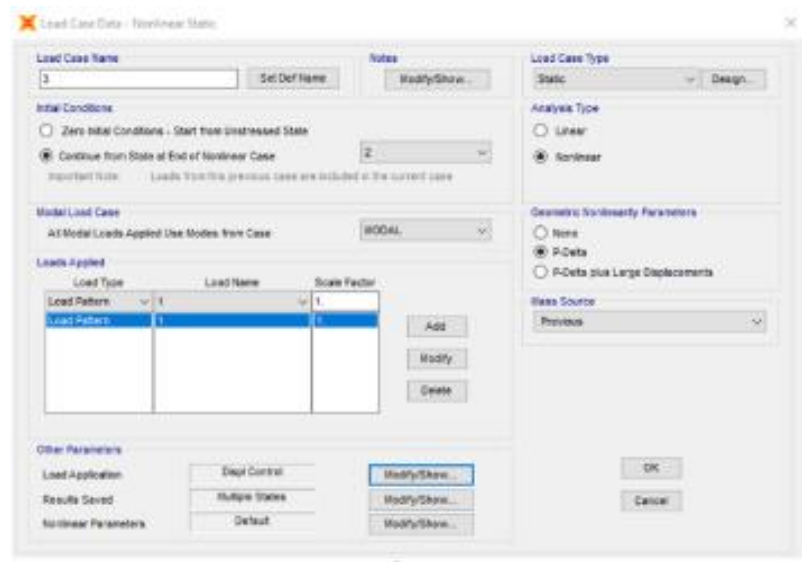

(b)

Figure 8. Loading History Definition in SAP2000 (a) Load Case, (b) Nonlinear Load Case Parameters

\section{Reference Database}

This research was conducted by referring to available experimental data from previous research [1,30-33]. The detail parameters of each model can be examined from Table 1. 
Table 1. Parameters of RC Beam-column Joints

\begin{tabular}{|c|c|c|c|c|c|c|c|c|}
\hline Specimen & $\begin{array}{c}\mathrm{f}_{\mathrm{c}} \\
(\mathrm{MPa})\end{array}$ & $\begin{array}{c}\mathrm{f}_{\mathrm{y}} \\
(\mathrm{MPa})\end{array}$ & $\begin{array}{c}\mathrm{P} \\
(\%)\end{array}$ & $\begin{array}{c}\text { BS } \\
(\mathrm{mm})\end{array}$ & $\begin{array}{c}\mathrm{ts} \\
\left(\mathrm{mm}^{2}\right)\end{array}$ & $\begin{array}{c}\mathrm{bs} \\
\left(\mathrm{mm}^{2}\right)\end{array}$ & $\mathrm{sr}$ & $\rho_{j}$ \\
\hline PEER-2250 [1] & 38.4 & 527.45 & 10 & $406.4 \times 508$ & 2327.69 & 1551.79 & 2 2\#4 & - \\
\hline PEER-0850 [1] & 34.97 & 462 & 10 & $406.4 \times 508$ & 774.19 & 774.19 & $2 \# 4$ & - \\
\hline S1 [31] & 32 & 440 & - & $350 \times 500$ & 3021.43 & 1520.53 & 2-D10 & 0.011 \\
\hline S2 [31] & 32 & 710 & - & $350 \times 500$ & 1900.66 & 1140.4 & 2-D10 & 0.011 \\
\hline S3 [31] & 32 & 710 & - & $350 \times 500$ & 1900.66 & 1140.4 & 2-D10 & 0.012 \\
\hline P1 [32] & 33.1 & 459 & 10 & $406.4 \times 406.4$ & 2580 & 2580 & 4.\#3 & - \\
\hline P2 [32] & 30.2 & 459 & 25 & $406.4 \times 406.4$ & 2580 & 2580 & 4-\#3 & - \\
\hline C2 [30] & 46.2 & 454 & 10 & $406.4 \times 406.4$ & 2580 & 2580 & 2\#3 & - \\
\hline C5 [30] & 37 & 454 & 25 & $406.4 \times 406.4$ & 2580 & 2580 & 2-\#3 & - \\
\hline C6 [30] & 40.1 & 454 & 10 & $406.4 \times 406.4$ & 2580 & 2580 & $2 \# 3$ & - \\
\hline BSL-300 [33] & 34.1 & 520 & 10 & $260 \times 300$ & 942.48 & 942.48 & 2-T10 & - \\
\hline BSL-450 [33] & 30.9 & 520 & 10 & $250 \times 450$ & 942.48 & 942.48 & 2-T10 & - \\
\hline
\end{tabular}

Notes:

$\mathrm{P} \quad$ ratio of axial load $\left(\mathrm{P} / \mathrm{A}_{\mathrm{g}} \mathrm{f}_{\mathrm{c}}\right)$

BS beam size (width $x$ height)

ts area of top steel reinforcement

bs area of bottom steel reinforcement

sr shear reinforcement of beam

$\rho_{j} \quad$ ratio of transverse steel reinforcement in the joint

\section{Results and Discussions}

The results of this study are presented based on the type of joints, i.e. interior and exterior joints. Interior joints include PEER-2250, PEER 0850, S1, S2 and S3 models, while the exterior joints include P1, P2, C2, C5, C6, BSL-300, and BSL-450 models. In the following sections, the term "model" is used to refer to the results of beam-column analysis using SAP2000.

\section{Interior Joints}

Figures 9 and 10 represent the comparison of hysteretic curves of experimental test and model for PEER-2250 and PEER-0850 specimens [1]. The experimental report indicates that the specimens suffered a combination of shear and bond-slip failure. Also, it is reported that joint cracks occurred at initial stage of loading cycles before the beam rebars yielded. After the beam yielding, the strength hardening took place and increased the ultimate capacity of the joints. Later, shear failure caused the strength and stiffness of the joints to degrade. The behavior of PEER-2250 can be represented very well by the model. However, the yielding of the beam occurred earlier than in the experimental test. This can be because the presence of the imposed axial loading, which can increase the shear capacity of the joint [34]. Meanwhile, for PEER0850 specimen, the model can also simulate the cyclic response considerably well. However, it is notable that the model strength did not degrade as much as those in the experimental results. This can be addressed by adjusting some parameters in the moment-rotation curve of the joint, since the failure of this specimen was governed by the combination of shear and bond-slip mechanism.

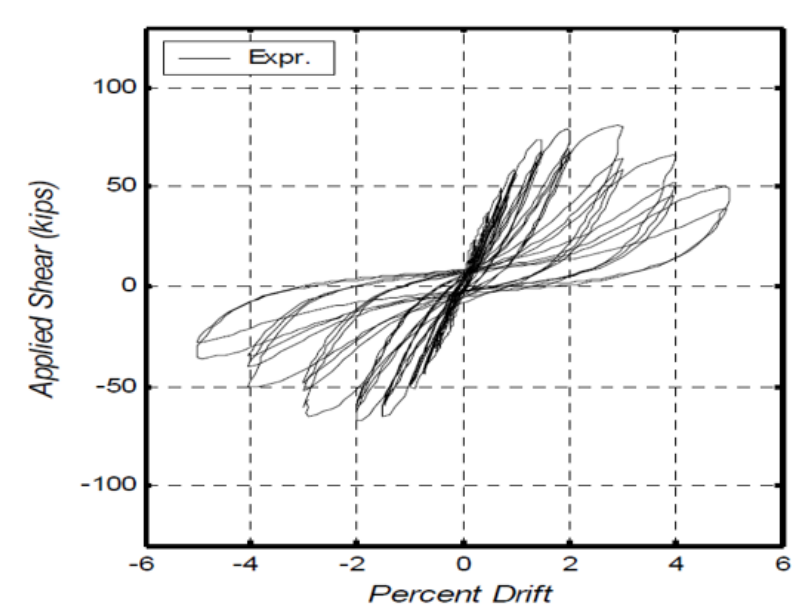

(a)

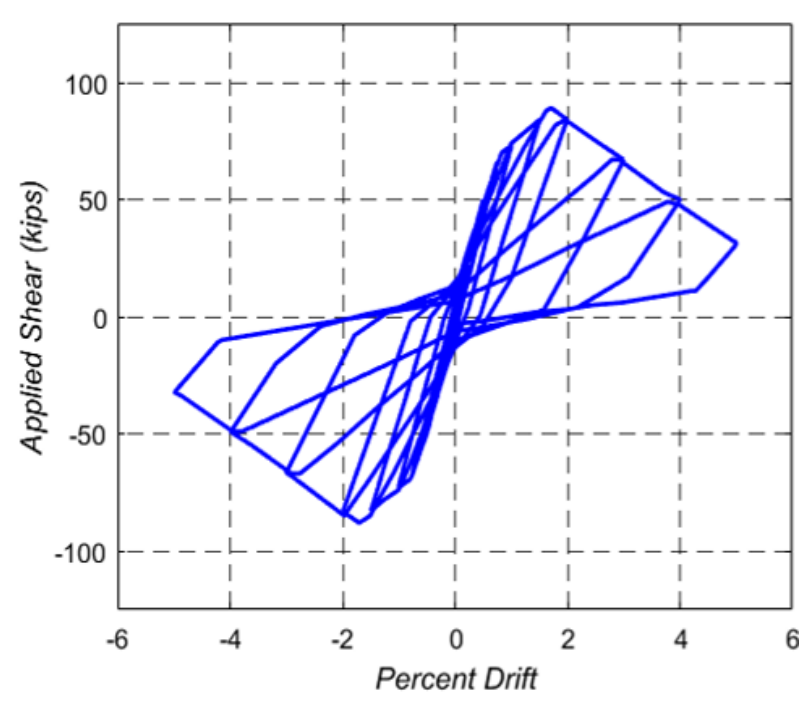

(b)

Figure 9. Comparison of Hysteretic Curves of Specimen PEER-2250 [1] (a) Test, (b) Model 


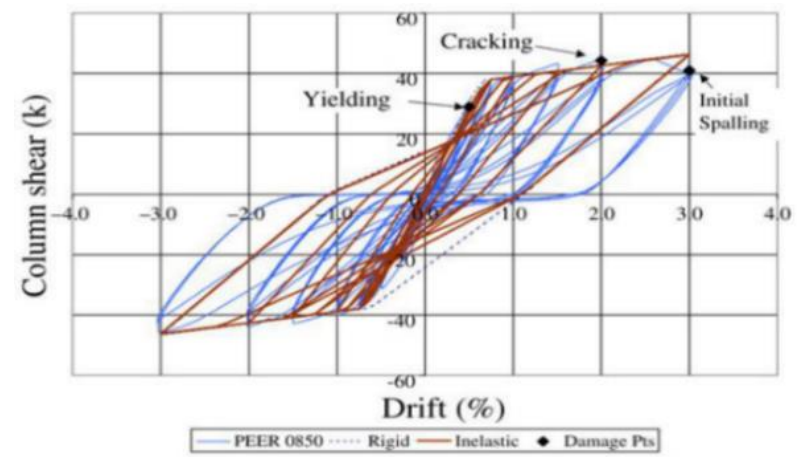

(a)

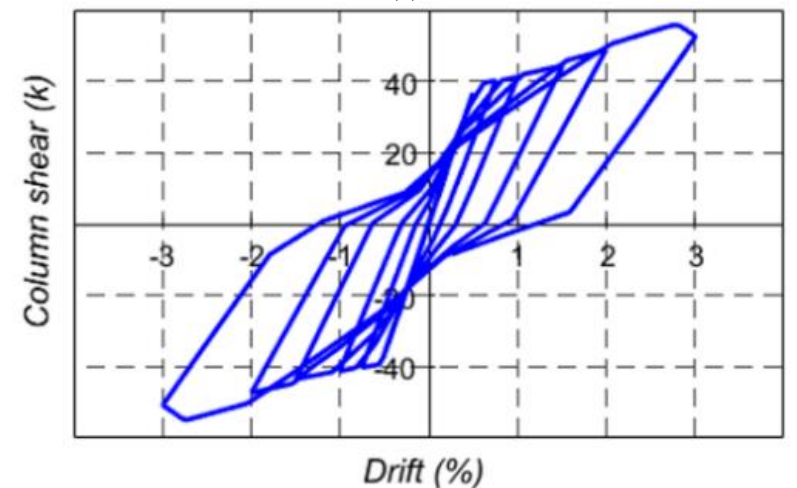

(b)

Figure 10. Comparison of Hysteretic Curves of Specimen PEER-0850 [1] (a) Test, (b) Model

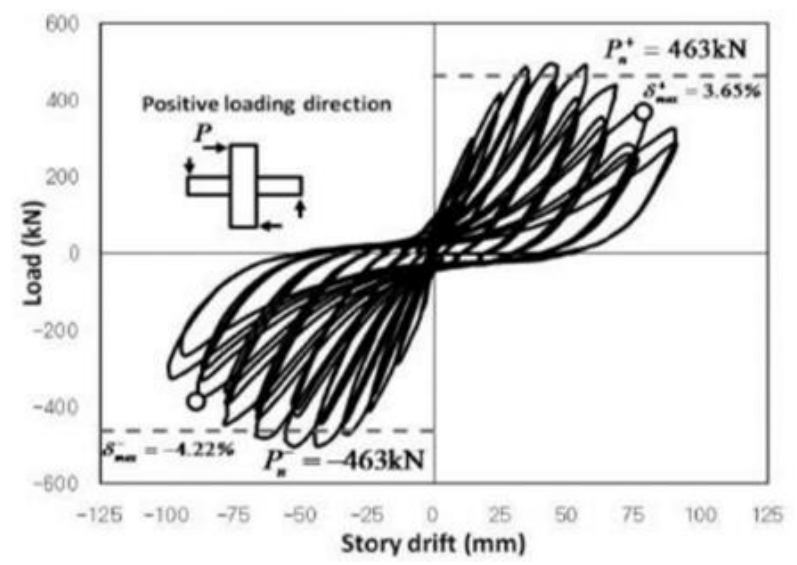

(a)

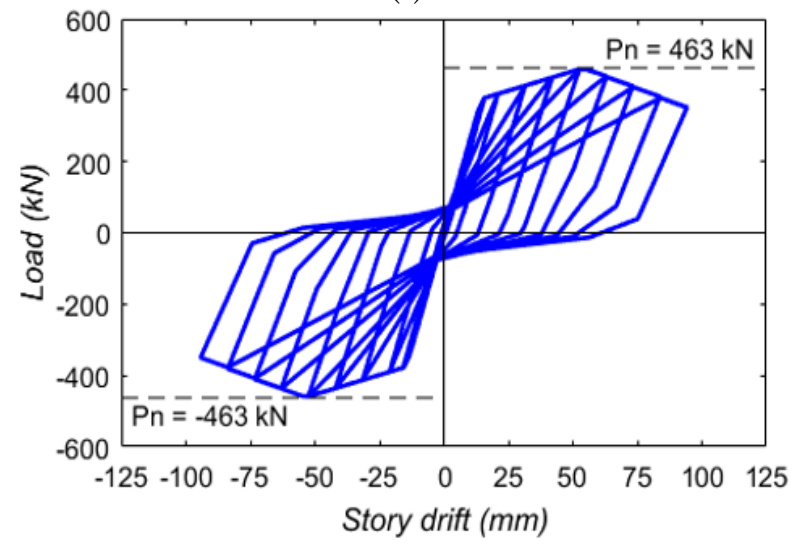

(b)

Figure 11. Comparison of Hysteretic Curves of Specimen S1 [31] (a) Test, (b) Model

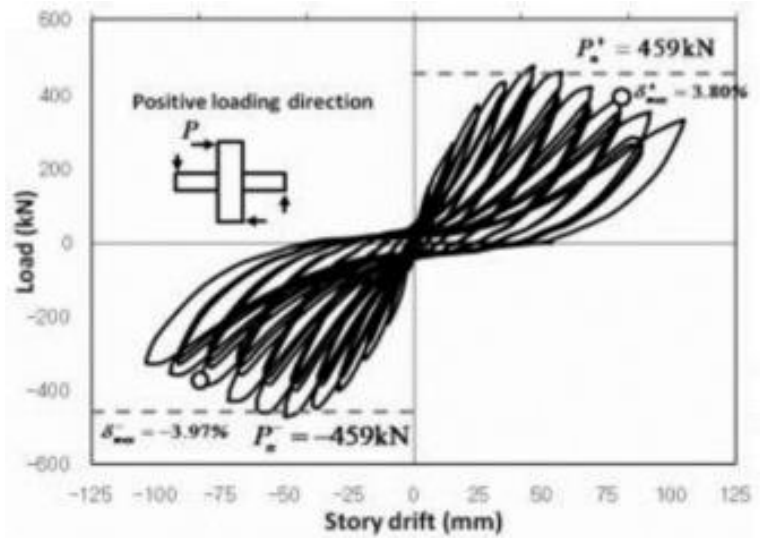

(a)

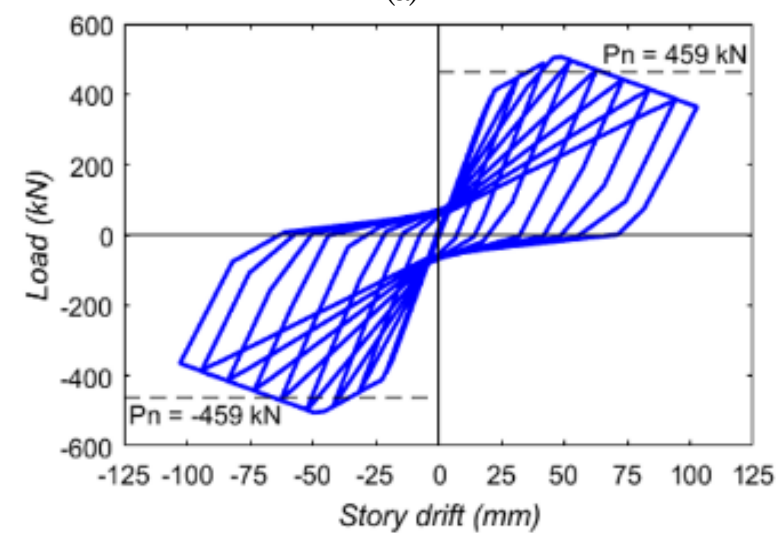

(b)

Figure 12. Comparison of Hysteretic Curves of Specimen S2 [31] (a) Test, (b) Model

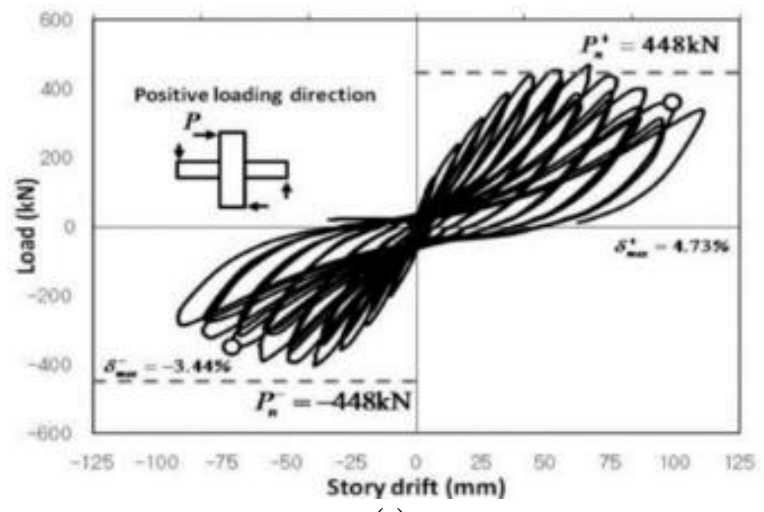

(a)

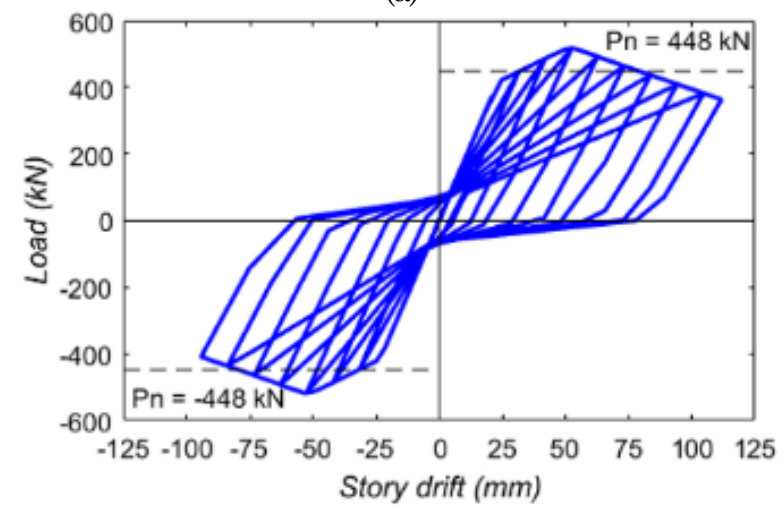

(b)

Figure 13. Comparison of Hysteretic Curve of Specimen S3 [31] (a) Test, (b) Model 
The comparison of hysteretic curves between experimental and analytical results are displayed on Figures 11, 12, and 13, for specimens S1, S2, and S3 [31], respectively. All three hysteretic loops show clear pinching shape with gradual stiffness degradation of the beam-column joints. It is reported that the specimens underwent bond-slip failure, which can be observed from the cyclic load-drift curve. Notable result from the experimental can be observed from S3 specimen, which is not symmetrical for loading in positive and negative directions. This is reported due to crack occurred when loading in one direction, and thus reducing the stiffness of beam-column joint when the loading reversely applied. From the simulated model for specimens S1, S2, dan S3 the results are considered representative for the experimental tests in terms of yielding load, ultimate load, as well as strength degradation. Specifically, for S3 specimen, the model can also produce nonsymmetrical hysteretic curves as obtained in the experimental test. This was possible by modifying the moment-rotation curve to represent beam yielding strength for different load directions.

\section{Exterior Joints}

The first comparisons of exterior beam-column joint hysteretic curves resulting from experimental tests and models, i.e. P1 and P2 [32], are shown in Figures 14 and 15, respectively. It is reported that those two specimens failed under bond-slip failure, and thus not allowing the beam to reach yielding phase. Other notable results that draw attention were the highly unsymmetrical cyclic load-displacement response of the specimens. This was because the difference of development length provided in the top and bottom steel reinforcement of the beam, resulting higher response for those face provided with capability to undergo yielding. To accommodate this distinct condition of top and bottom steel reinforcement, a simple modification of moment-rotation was used for the beams. As the results, the model can simulate the behavior of these two specimens. However, it is also notable that the model exhibits slightly higher lateral load capacity in downward loading direction. This is because the specimens underwent shear failure, which is until now the model cannot represent it perfectly. Yet, the overall shape of the hysteretic curves is highly identical.

The subsequence figures, i.e. Figures 16, 17, and 18 show the comparison of hysteretic curve between experimental and simulation results for $\mathrm{C} 2$, C5, and C6 specimens [30], respectively. The tested specimens were reported to induce crack at initial stages of loading cycles and further loadings caused significant stiffness degradation of the joints. Finally, the joints underwent shear failure when reaching their ultimate loading cycles. For all three specimens, the simulated model can reproduce identical hysteresis loops at yielding and strength hardening region. However, the model cannot perfectly mimic the beamcolumn joint behavior at the degrading portion of the hysteresis loop. The model provides higher strength at maximum drift. This can be indicator that the model still cannot perfectly simulate the behavior of the joint which failure is categorized as joint shear failure.

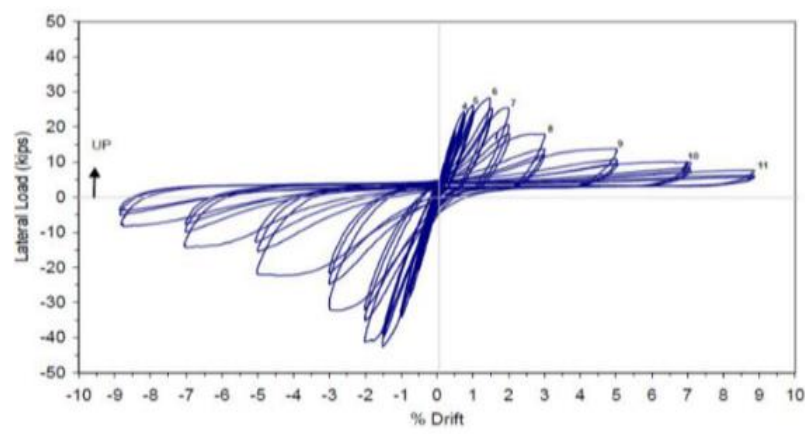

(a)

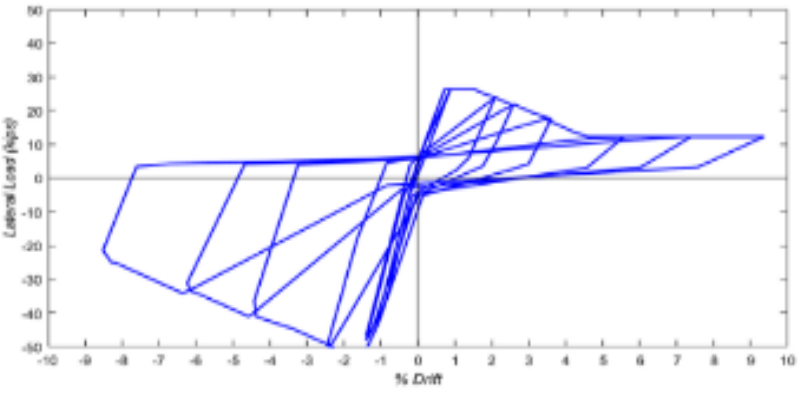

(b)

Figure 14. Comparison of Hysteretic Curve of Specimen P1 [32] (a) Test, (b) Model

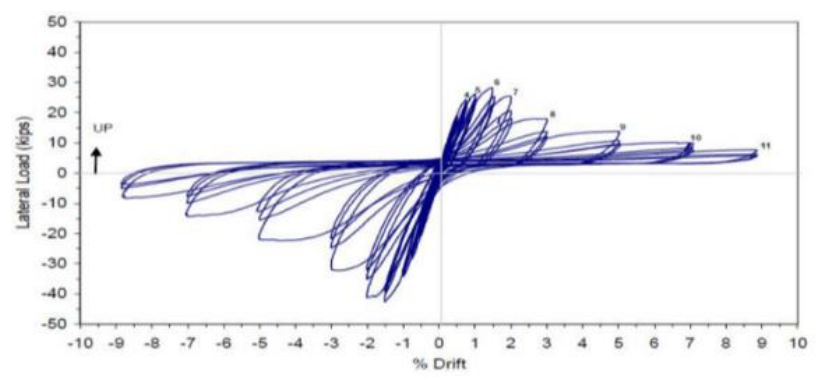

(a)

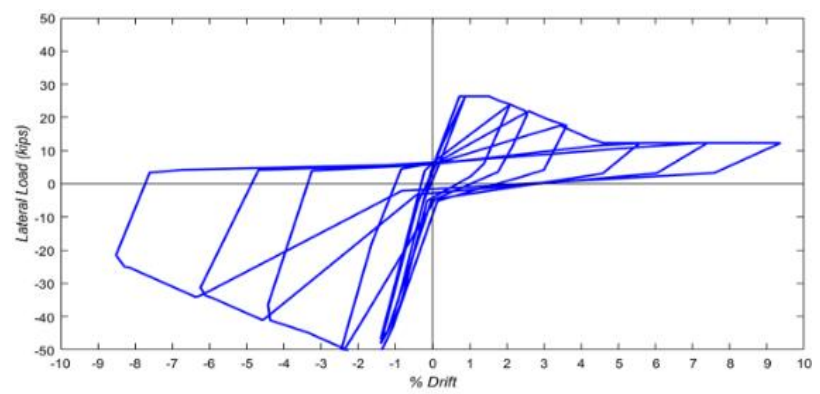

(b)

Figure 15. Comparison of Hysteretic Curve of Specimen P2 [32] (a) Test, (b) Model 


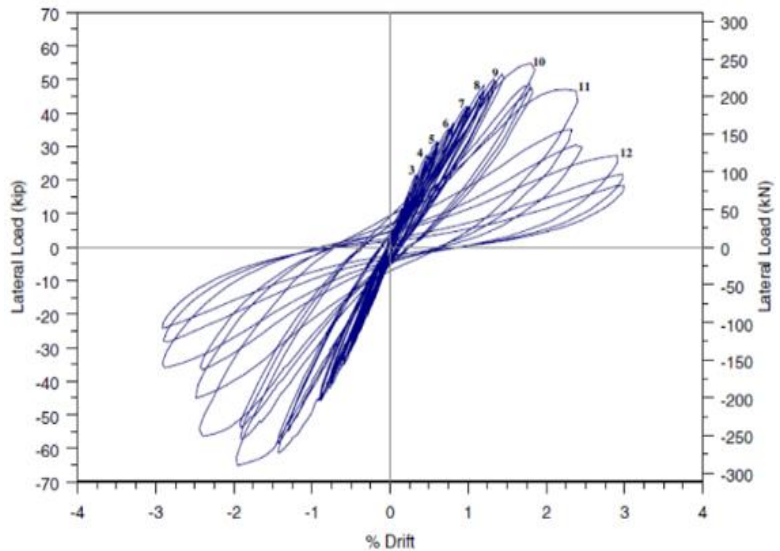

(a)

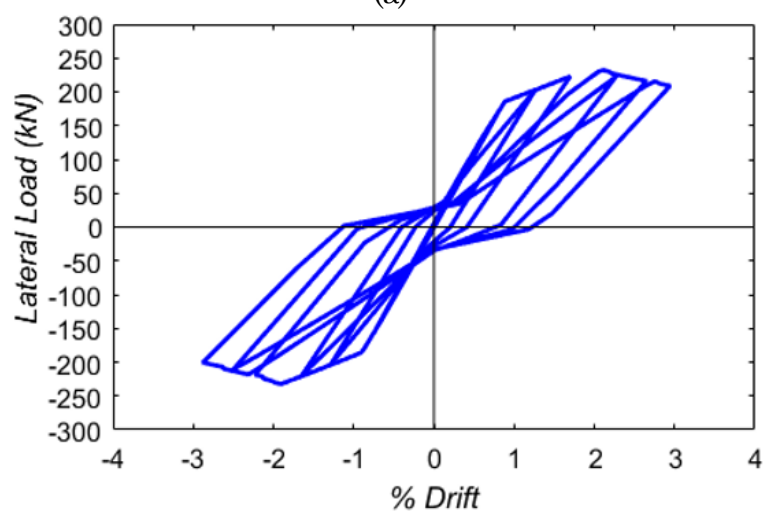

(b)

Figure 16. Comparison of Hysteretic Curve of Specimen C2 [30] (a) Test, (b) Model

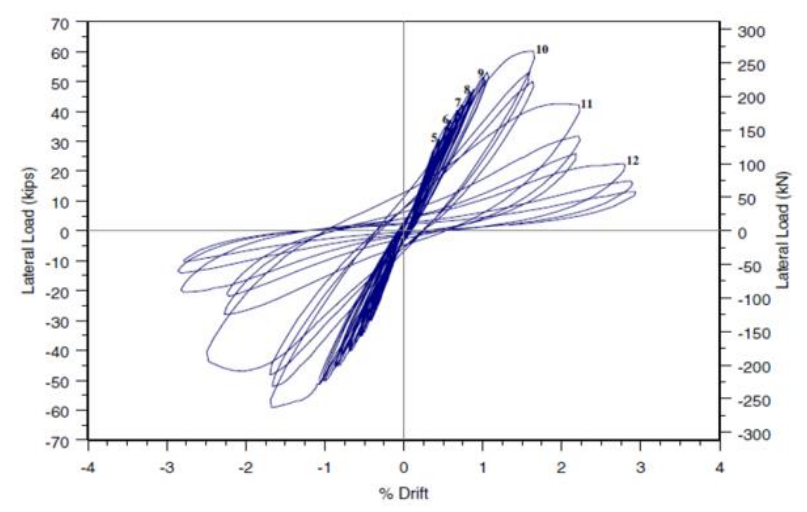

(a)

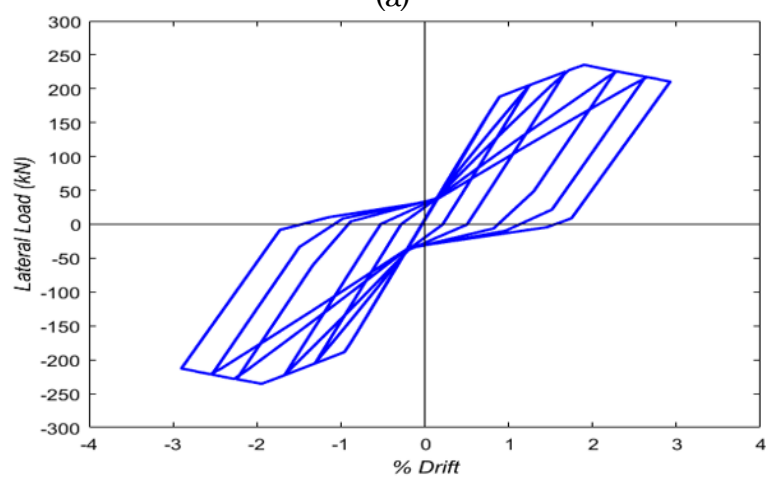

(b)

Figure 17. Comparison of Hysteretic Curve of Specimen C5 [30] (a) Test, (b) Model

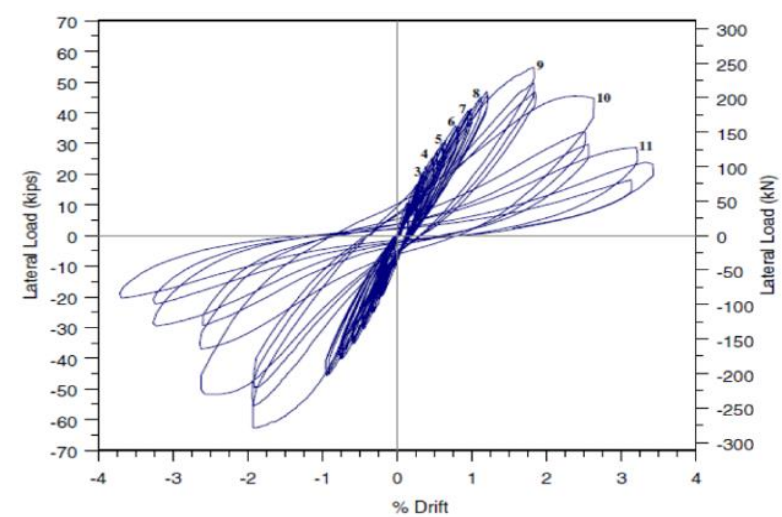

(a)

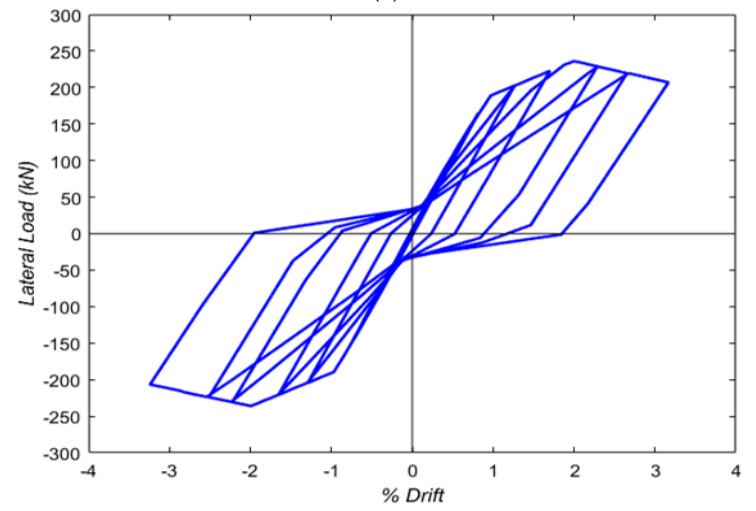

(b)

Figure 18. Comparison of Hysteretic Curve of Specimen C6 [30] (a) Test, (b) Model

Figures 19 and 20 show the comparison of hysteretic curves for specimen BSL-300 and BSL-450 [33], respectively. From both figures, it is obvious that the experimental tests resulted hysteretic loop with pinching presents. This indicates both specimens have poor seismic performance in case of the amount of energy can be dissipated. Also, the experimental test shows that BSL-300 specimen slightly exceeds beam capacity before it degrades. Meanwhile, for BSL-450 specimen the joint failed even before the beam yielded. Both specimens were reported to fail due to crushing of diagonal compression strut in the joints. The simulated models show remarkable outcome. BSL-300 model shows hysteretic curve with generally identical shape to those of experimental results. The ultimate shear force in the hysteretic curve resulted from the model is slightly higher compared to beam flexural capacity, which is confirmed by experimental result. Also, the stiffness degradation of the beam-column joint is considered similar. On the other hand, distinct result is clear in case of BSL-450 specimen. Firstly, the result from the model shows less notable pinching in the hysteretic curve. Secondly, flexural strength of the beam was slightly exceeded, which is clearly different to the experimental result. Thirdly, the overall hysteretic loops of the model did not significantly degrade as those from experimental test. The evidence that the simulation of BSL-300 specimen yields considerably 
good result, while it is not the case for BSL-450 specimen, is because BSL-450 specimen failed due to shear prior to beam flexural yielding. This might be evidence that the current model cannot simulate well the nonlinear cyclic behavior of RC beam-column joint failing in joint shear which is not initiated by yielding of the beams.

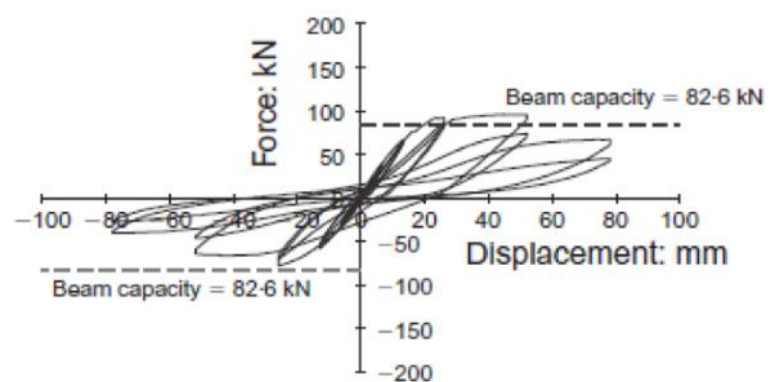

(a)

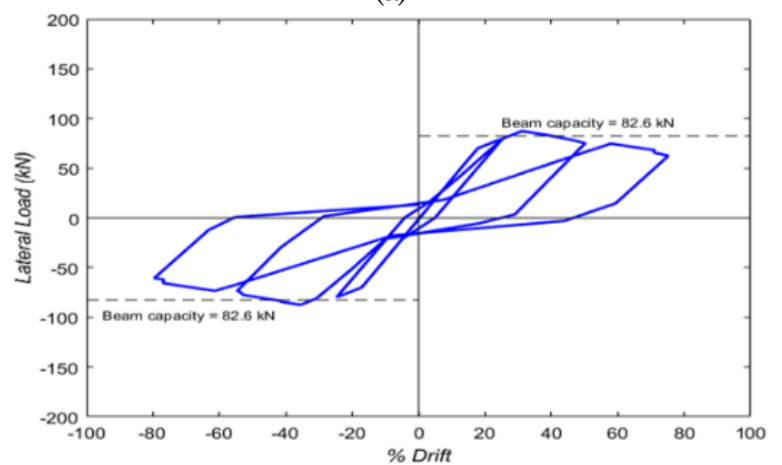

(b)

Figure 19. Comparison of Hysteretic Curve of Specimen BSL-300 [33] (a) Test, (b) Model

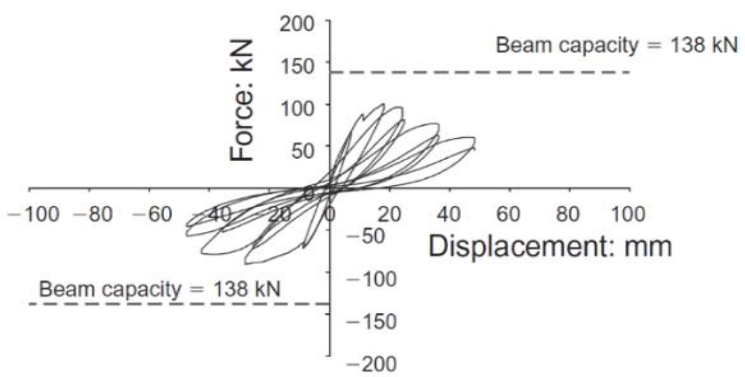

(a)

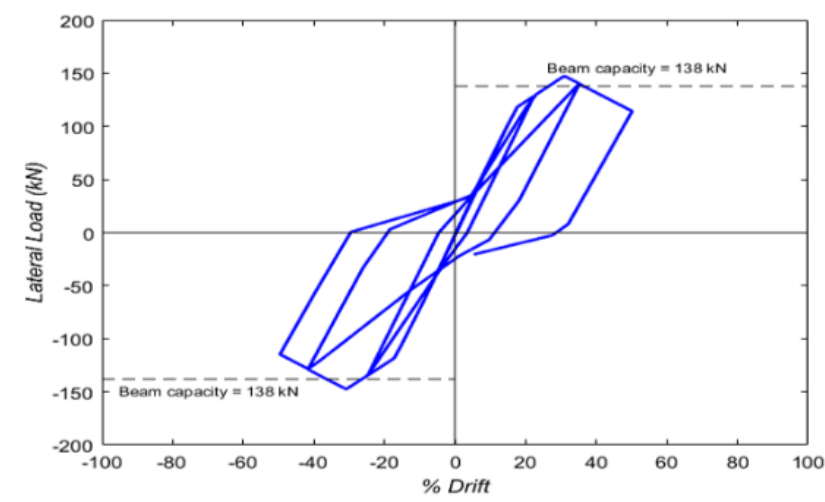

(b)

Figure 20. Comparison of Hysteretic Curve of Specimen BSL-450 [33] (a) Test, (b) Model
More detail results of the simulated beam-column interior and exterior joints can also be found in the works by Octaviani and Chiaulina [35].

\section{Conclusions}

Five interior and seven exterior RC beam-column joint specimens have been studied using the simply modified lump plasticity model. After comparing the results from available experimental tests and simulated models, the following concluding remarks are listed.

1. The model can be used to simulate cyclic loading response of $\mathrm{RC}$ beam-column joint which failure is initiated by beam yielding such in PEER-2250 and PEER-0850 specimens.

2. The nonsymmetrical flexural strength of beams due to reverse loading can be easily simulated in the model by defining different moment-rotation relationship for beam as is demonstrated in $\mathrm{S} 1$, S2, and S3 specimens.

3. The model can exhibit the response of beamcolumn joint under reversal loadings with bondslip failure mechanism by modifying the bond-slip parameters of the beams according to provided development length, which is established in simulating $\mathrm{P} 1$ and $\mathrm{P} 2$ specimens.

4. The model cannot perfectly simulate the degrading portion of the hysteretic curves of $\mathrm{RC}$ beamcolumn joints failing in joint shear, i.e. for C2, C5, and $\mathrm{C} 6$ specimens, where the stiffness of the joints in the models are considered stiffer compared to those from experimental tests.

5. The model can simulate the behavior of RC beamcolumn joint failing in joint shear mode if it is initiated by yielding of the beams, which is obvious in simulation result of BSL-300 specimen. However, the model cannot simulate well the behavior of RC beam-column joint failing in joint shear that is not initiated by yielding of the beams, as shown in simulation result of BSL-450 specimen.

Future works can be aimed to develop the model such that it can perfectly simulate the joint shear failure of $\mathrm{RC}$ beam-column joint, including the degrading portion of the hysteretic curve.

\section{References}

1. Walker, S.G., Seismic Performance of Existing Reinforced Concrete Beam-Column Joints, University of Washington, 2001.

2. Omidi, M. and Behnamfar, F., A Numerical Model for Simulation of RC Beam-Column Connections, Engineering Structures, 88(2015), 2015, pp. 51-73. 
3. Giberson, M.F., Two Nonlinear Beams with Definitions of Ductility, Journal of the Structural Division, ASCE, 95(ST2), 1969, pp. 137-157.

4. Otani, S., Inelastic Analysis of R/C Frame Structures, Journal of the Structural Division, ASCE, 100(Proc. Paper 10686), 1974.

5. Banon, H., Irvine, H.M., and Biggs, J.M., Seismic Damage in Reinforced Concrete Frames, Journal of the Structural Division, ASCE, 107(9), 1981, pp. 1713-1729.

6. Alath, S., Modeling Inelastic Shear Deformation in Reinforced Concrete Beam-Column Joints, University of Central Florida, 1995.

7. Biddah, A., and Ghobarah, A., Modelling of Shear Deformation and Bond Slip in Reinforced Concrete Joints, Journal of Engineering and Mechanics, 7(4), 1999, pp. 413-432.

8. Elmorsi, M., Kianoush, M.R., and Tso, W.K., Modeling Bond-Slip Deformations in Reinforced Concrete Beam-Column Joints, Canadian Journal of Civil Engineering, 27(3), 2000, pp. 490-505.

9. Youssef, M. and Ghobarah, A., Modelling of RC Beam-Column Joints and Structural Walls, Journal of Earthquake Engineering, 5(01), 2001, pp. 93-111.

10. Pampanin, S., Magenes, G., and Carr, A.J., Modelling of Shear Hinge Mechanism in Poorly Detailed RC Beam-Column Joints, Fib 2003 Symposium Concrete Structures in Seismic Regions, Athens, Greece, 2003.

11. Lowes, L.N. and Altoontash, A., Modeling Reinforced-Concrete Beam-Column Joints Subjected to Cyclic Loading, Journal of Structural Engineering, 129(12), 2003, pp. 1686-1697.

12. Shin, M. and LaFave, J.M., Modeling of Cyclic Joint Shear Deformation Contributions in RC Beam-Column Connections to Overall Frame Behavior, Journal of Structural Engineering and Mechanics, 18(5), 2004, pp. 645-669.

13. Tajiri, S., Shiohara, H., and Kusuhara, F., A New Macroelement of Reinforced Concrete Beam Column Joint for Elasto-Plastic Plane Frame Analysis, Proc. 8th. National Conf. Earthquake Engineering, 2006.

14. Mitra, N. and Lowes, L.N., Evaluation and Advancement of a Reinforced Concrete BeamColumn Joint Model, 13th World Conference on Earthquake Engineering, 2004, pp. 1001.

15. Magliulo, G. and Ramasco, R., Seismic Response of Three-dimensional r/c Multi-storey Frame Building under Uni and Bi-directional Input Ground Motion, Earthquake Engineering \& Structural Dynamics, 36(12), 2007, pp. 16411657.

16. Anderson, M., Lehman, D., and Stanton, J., A Cyclic Shear Stress-Strain Model for Joints without Transverse Reinforcement, Engineering Structures, 30(4), 2008, pp. 941-954.
17. Wang, G.-L., Dai, J.-G., and Teng, J.G., Shear Strength Model for RC Beam-Column Joints under Seismic Loading, Engineering Structures, 40(2012), 2012, pp. 350-360.

18. Birely, A.C., Lowes, L.N., and Lehman, D.E., A Model for the Practical Nonlinear Analysis of Reinforced-Concrete Frames Including Joint Flexibility, Engineering Structures, 34(2012), 2012, pp. 455-465.

19. Yu, J. and Tan, K.-H., Experimental and Numerical Investigation on Progressive Collapse Resistance of Reinforced Concrete Beam Column SubAssemblages, Engineering Structures, 55(2013), 2013, pp. 90-106.

20. Eom, T.-S., Hwang, H.-J., and Park, H.-G., Energy-based Hysteresis Model for Reinforced Concrete Beam-Column Connections, ACI Structural Journal, 112(2), 2015, pp. 157.

21. Ngo, D. and Scordelis, A.C., Finite Element Analysis of Reinforced Concrete Beams, ACI Journal, 64(3), 1967, pp. 152-163.

22. Nilson, A.H., Internal Measurement of Bond Slip, ACI Journal, 69(7), 1972, pp. 439-441.

23. Keuser, M. and Mehlhorn, G., Finite Element Models for Bond Problems, Journal of Structural Engineering, 113(10), 1987, pp. 2160-2173.

24. Filippou, F.C., A Simple Model for Reinforcing Bar Anchorages under Cyclic Excitations, Journal of Structural Engineering, 112(7), 1986, pp. 1639-1659.

25. Monti, G., Filippou, F.C., and Spacone, E., Finite Element for Anchored Bars under Cyclic Load Reversals, Journal of Structural Engineering, 123(5), 1997, pp. 614-623.

26. Ciampi, V., Eligehausen, R., Bertero, V.V., and Popov, E.P., Analytical Model for Concrete Anchorages of Reinforcing Bars under Generalized Excitations, College of Engineering, University of California Berkeley, CA, USA, 1982.

27. Eligehausen, R., Popov, E.P., and Bertero, V.V., Local Bond Stress-Slip Relationships of Deformed Bars under Generalized Excitations, Proceedings of the 7th European Conference on Earthquake Engineering, Athens, Greece, 1982.

28. Mander, J.B., Priestley, M.J., and Park, R., Theoretical Stress-Strain Model for Confined Concrete, Journal of Structural Engineering, 114(8), 1988, pp. 1804-1826.

29. Park, R., Ductility Evaluation from Laboratory and Analytical Testing, Proceedings of the 9th World Conference on Earthquake Engineering, Tokyo-Kyoto, Japan, 1988, pp. 605-616.

30. Clyde, C., Pantelides, C.P., and Reaveley, L.D., Performance-Based Evaluation of Exterior Reinforced Concrete Building Joints for Seismic Excitation, Pacific Earthquake Engineering Research Center, College of Engineering, University of California, Berkeley, 2000. 
31. Hwang, H.-J., Park, H.-G., Choi, W.-S., Chung, L., and Kim, J.-K., Seismic Performance of BeamColumn Connections for Special Moment Frame Using $600 \mathrm{MPa}$ Flexural Reinforcement, Journal of the Korea Concrete Institute, 23(5), 2011, pp. 591-601.

32. Pantelides, C.P., Clyde, C., and Reaveley, L.D., Performance-Based Evaluation of Reinforced Concrete Building Exterior Joints for Seismic Excitation, Earthquake Spectra, 18(3), 2002, pp. 449-480.
33. Wong, H.F. and Kuang, J.S., Effects of BeamColumn Depth Ratio on Joint Seismic Behaviour, Proceedings of the Institution of Civil EngineersStructures and Buildings, 161(2), 2008, pp. 91-101.

34. Fu, J., Chen, T., Wang, Z., and Bai, S., Effect of Axial Load Ratio on Seismic Behavior of Interior Beam-Column Joints, Proc. 12th World Conf. Earthquake Eng, 2000.

35. Octaviani, V., and Chiaulina, P.K., Evaluasi Permodelan Non-Ductile Beam-Column Joint, Undergraduate Thesis, Petra Christian University, Surabaya, Indonesia, 2018. 